This document is the accepted manuscript version of the following article:

Sheima, Y., Caspari, P., \& opris, D. M. (2019). Artificial muscles: dielectric

elastomers responsive to low voltages. Macromolecular Rapid Communications, 1900205 (8

pp.). https://doi .org/10.1002/marc. 201900205

DOI: 10.1002/ ((please add manuscript number))

Article type: ((Concept, Feature Article, Full Paper, Progress Report, Research News, Review))

\title{
Artificial muscles: dielectric elastomers responsive to low voltages
}

Yauhen Sheima, Philip Caspari, and Dorina M. Opris*

Y. Sheima, P. Caspari, Dr. D. M. Opris

Swiss Federal Laboratories for Materials Science and Technology Empa, Laboratory for Functional Polymers, Ueberlandstr. 129, CH-8600, Dübendorf, Switzerland

E-mail: dorina.opris@empa.ch

Y. Sheima, P. Caspari

Ecole Polytechnique Fédérale de Lausanne (EPFL), Institut des Matériaux, Station 12, CH 1015, Lausanne, Switzerland

Keywords: dielectric elastomer actuators, high permittivity elastomers, high permittivity polysiloxanes, thiol-ene addition, thin films

\section{Abstract}

The lack of soft high-dielectric permittivity elastomers responsive to a low voltage has been a long-standing obstacle for the industrialization of dielectric elastomer actuators (DEA) technology. Here, elastomers that do not only possess high dielectric permittivity of 18 and good elastic and insulating properties, but are also processable in very thin films by conventional techniques are reported. Additionally, the elastic modulus can be easily tuned by the type of cross-linker used. A soft elastomer with a storage modulus of $E=350 \mathrm{kPa}$, a $\tan \delta$ $=0.007$ at $0.05 \mathrm{~Hz}$, and a lateral actuation strain of $13 \%$ at $13 \mathrm{~V} / \mu \mathrm{m}$ is prepared. A stable lateral actuation over 50000 cycles at $10 \mathrm{~Hz}$ is demonstrated. A stiffer elastomer with a storage modulus $E=790 \mathrm{kPa}$, a $\tan \delta=0.0018$ at $0.05 \mathrm{~Hz}$, a large out of plane actuation at 41 $\mathrm{V} / \mu \mathrm{m}$, and breakdown fields of almost $100 \mathrm{~V} / \mu \mathrm{m}$ is also developed. Such breakdown fields in actuators are the highest ever reported for a high-permittivity elastomer. Additionally, actuators operable at a voltage as low as $200 \mathrm{~V}$ are also demonstrated. Because the materials used are cheap and easily available, and the chemical reactions leading to them allow upscaling, they have the potential to advance the DEA technology. 


\section{Introduction}

Soft and elastic capacitors, also known as dielectric elastomer actuators (DEA), reversibly change their shape under an electric stimulus. ${ }^{[1]}$ Their rather simple construction and operation and the fact that they mimic natural muscles gave them the name of artificial muscles. $^{[2]}$ A large variety of prototypes were constructed, which one day will find applications in automobiles, robotics, electronics, aerospace, medical products and medicine. ${ }^{[3,4]}$ While a large variety of insulating elastomers can be used as dielectric, ${ }^{[5-9]}$ one issue associated with the DEA technology is the high driving voltage required for actuation, which is in the $\mathrm{kV}$ range. ${ }^{[10]}$

Attempts to reduce the driving voltage include decreasing film thickness, reducing the elastic modulus, and increasing the dielectric permittivity of the dielectric elastomer used. Thickness reduction is attractive since both actuation strain as well as actuation pressure increase inversely proportional to the squared thickness. ${ }^{[11]}$ Previous work showed that actuators constructed from a $3 \mu \mathrm{m}$ thin silicone elastomer film $\left(\varepsilon^{\prime} \sim 3\right)$ gave $7.5 \%$ lateral actuation at $245 \mathrm{~V} \cdot{ }^{[12]} \mathrm{A}$ further reduction of the thickness of the silicone elastomer to $1.4 \mu \mathrm{m}$ allowed access to actuators driven at $100 \mathrm{~V} .^{[13]}$ Although these results are promising, the implementation of such thin films in DEA large-scale production is challenging, since a thickness reduction of the dielectric films below $20 \mu \mathrm{m}$ is associated with increased fabrication costs. ${ }^{[14]}$ Additionally, the mechanical properties of electrodes have a strong impact on actuation especially when ultra-thin films are used. ${ }^{[12]}$ Low voltage actuators can be in principle achieved with soft elastomers. They can be prepared either by reducing the crosslinking density, ${ }^{[15]}$ using plasticizers, ${ }^{[16]}$ synthesizing bimodal heterogeneous networks, ${ }^{[17]}$ or incorporating bottlebrush segments into the polymer network. ${ }^{[18]}$ However, the dielectric breakdown of such soft elastomers is a hurdle still to be overcome. ${ }^{[19-21]}$ Moreover, because these elastomers have a low permittivity, their actuation pressure is also rather low. ${ }^{[1]}$ Though 
challenging, the last approach is nevertheless the most promising, since it does not only allow reducing the driving voltage, but also increasing the actuation pressure.

Materials solutions to high dielectric permittivity elastomers include blending the elastomer with highly polarizable fillers or chemical modification with polar groups. Both approaches are however limited either by an increased stiffness or a reduced breakdown field, or both. ${ }^{[7,8]}$ Additionally, thin film formation turns challenging, especially for blends. Chemical modification of polymers with polar groups is associated by a large increase in the glass transition temperature. ${ }^{[8]}$ It is therefore not surprising that only few polymers furnish low $T_{g}$ materials after chemical modification with polar groups. A polymer class that meets this requirement is polysiloxane. Their modification by the polar nitrile groups allowed formation of elastomers with $\varepsilon^{\prime}$ of about 18, which is amongst the highest dielectric permittivity value reported for polysiloxanes. ${ }^{[22-25]}$ Furthermore, they actuate at rather low electric fields of $10 \mathrm{~V} / \mu \mathrm{m}$. While all this looks attractive, it turned out to be challenging to process the material into sufficiently thin films under technologically relevant conditions. Because it was not possible to reduce the thickness of the films below $100 \mu \mathrm{m}$, the required actuation voltage was still above $1000 \mathrm{~V} .^{[23]}$

Up to date, there are no actuators reported that use high permittivity elastomers which can be processed into very thin films. Such actuators are expected to be operated at attractively low voltages, while still generating a reasonable actuation pressure. ${ }^{[12]}$ The desired elastomer combines properties such as good elasticity, low elastic modulus, low viscoelastic losses, high dielectric permittivity, high breakdown field, low leakage current density, and last but not least - processability in very thin films. This is the point where the current work sets in. We have developed a new synthetic pathway to nitrile modified polysiloxane elastomers with high dielectric permittivity, which can be processed into very thin films. Furthermore, the elastic modulus can be easily tuned by the amount and type of cross-linker used. This led 
to intriguing materials that actuate at unprecedentedly low voltages and low electric fields. Additionally, materials with large actuation and unprecedentedly high dielectric breakdown were developed.

\section{Results and Discussions}

In contrast to previous reports on nitrile-functionalized silicones prepared by an in situ process in which the functionalization with nitrile groups and the cross-linking into thin films occurred simultaneously, here we split the synthesis into two steps (Figure 1a). ${ }^{[21,23]}$ First, the polysiloxane was functionalized with polar groups and then purified via a dissolutionprecipitation step. In an independent second step, this material was processed into films of desired thickness and then cross-linked. More concretely, a polymethylvinylsiloxane of high molar mass $\left(\mathrm{M}_{n}=84800 \mathrm{Da}, \mathrm{M}_{w}=192000 \mathrm{Da}\right.$, and a $\left.P D I=2.3\right)$ was modified with 3mercaptopropionitrile at a stoichiometry to leave some vinyl groups unreacted (0.95 eq. 3mercaptopropionitrile to vinyl). The resulting polymer $\mathbf{P 1}$ was obtained several times on the 5 g scale, followed by a 40 g preparation. Repeated precipitation of a THF solution of P1 into methanol afforded pure material, which was conveniently stored as $40 \mathrm{wt} \%$ solution in THF. For relevant NMR spectra see Figure S1. NMR spectroscopy gave a vinyl content of P1 of 2.35\% (Figure S2), which is somewhat lower than the expected 5\%. The reason for this was not investigated, but is likely due to a side reaction between the vinyl groups during thiol addition. The GPC elugram of $\mathbf{P 1}$ is slightly broader as compared to the starting polymer (Figure S3), which may indicate this side reaction occurs intermolecular despite the fact that the reagents were diluted. 
a)

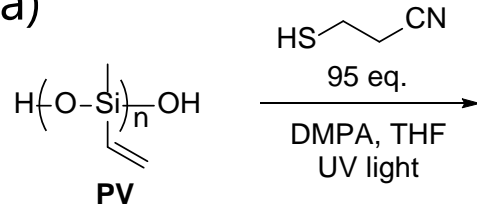

b)<smiles>O=C(CCS)OCC(COC(=O)CCS)(COC(=O)CCS)COC(=O)CCS</smiles>

c)
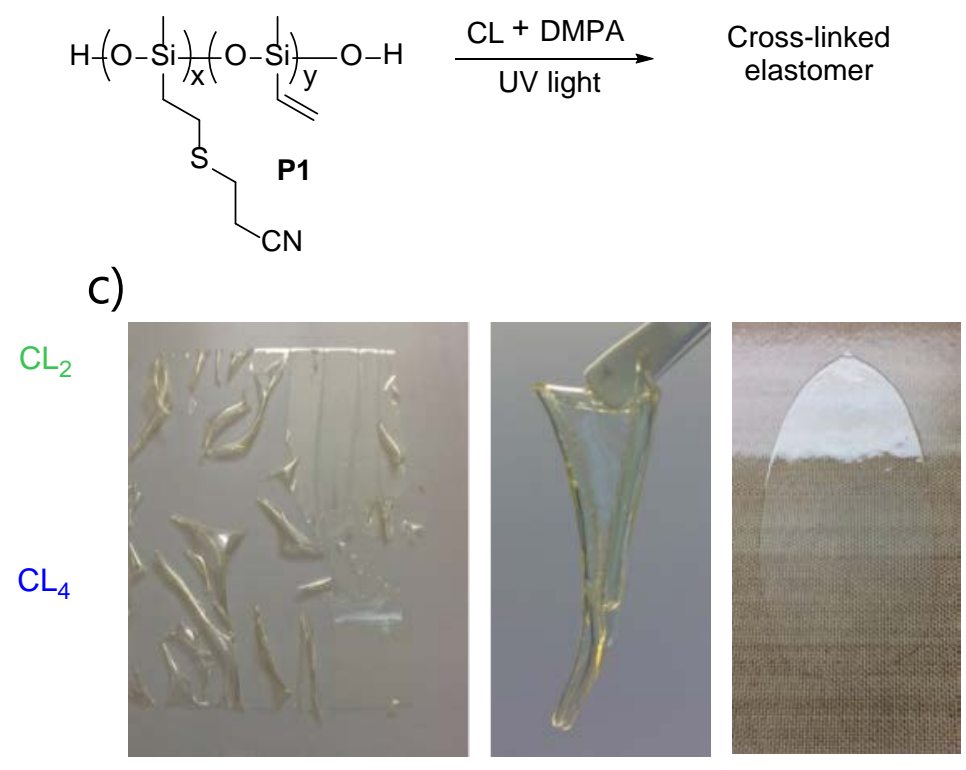

d)
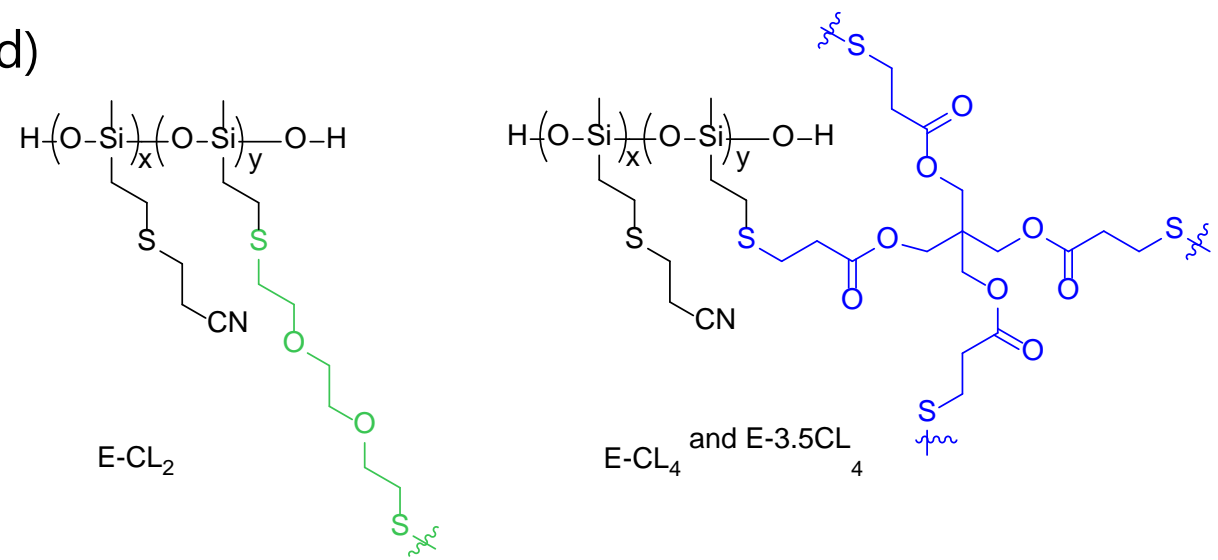

Figure 1. a) Synthesis of polysiloxane $\mathbf{P 1}$ containing polar nitrile and unreacted vinyl groups starting from polymethylvinylsiloxane via thiol-ene reaction and its cross-linking to elastomers via a thiol-ene reaction in presence of DMPA UV-light initiator. b) Chemical structures of the thiols used as cross-linkers: 2,2'-(ethylenedioxy)diethanethiol $\left(\mathbf{C L}_{2}\right)$ and pentaerythritol tetrakis(3-mercaptopropionate) $\left(\mathbf{C L}_{\mathbf{4}}\right)$. c) Photographs of a "thick" film which ruptured after cross-linking (left), which curled after it was detached from the substrate (middle), and of a smooth film, which neither ruptured nor curled (right). d) The idealized structure of the chemical network formed.

In the second step, thin films were prepared using dilute THF solutions of P1, multifunctional thiol cross-linker and photoinitiator. This way, the viscosity was kept low such that simple doctor blading afforded the desired homogeneous films, which were cross-linked by exposure to UV light. Two different cross-linkers (Figure 1b) 2,2'-(ethylenedioxy)diethanethiol $\left(\mathrm{CL}_{2}\right)$ and pentaerythritol tetrakis(3-mercaptopropionate) $\left(\mathrm{CL}_{4}\right)$ were tested. As it will be explained later, thicker films $(\sim 100 \mu \mathrm{m})$ for the dielectric and mechanical characterizations and thin 
films (20 $\mu \mathrm{m}$ to $55 \mu \mathrm{m}$ ) for electromechanical tests were prepared. The amounts of reagents used for each material denoted as E-CL $2, \mathbf{E}-\mathbf{C L}_{4}$, and $\mathbf{E}-\mathbf{3 . 5 C} \mathbf{L}_{4}$ are presented in Table 1.

We initially processed the material into thick films using a Teflon substrate. As mentioned above, a solution of $\mathbf{P 1}$ in THF had to be used, to adjust $\mathbf{P 1}$ viscosity such that the processing into thin films is possible. However, thicker films $(>80 \mu \mathrm{m})$ ruptured when not immediately detached from substrate, and upon detaching, they underwent spontaneous extreme bending (Figure 1c). Reducing film thickness to $30 \mu \mathrm{m}$ hindered rupturing on the substrate, but the films turned too fragile to be peeled off the substrate without tearing. Therefore, the film formation process was optimized. Self-rupturing of thick films may be due to the internal stress generated during UV-curing because of solvent evaporation. ${ }^{[26]}$ To overcome the above mentioned problem, the films were allowed to stand for $1 \mathrm{~h}$ at room temperature prior to cross-linking. This time was sufficient to evaporate most solvent. After UV irradiation, smooth films which neither ruptured nor curled formed.

Figure 2a shows the stress-strain curves of different materials, which represent the average of three different samples. The strain at break represents the lowest value obtained from the three measurements. Elastomer $\mathbf{E}-\mathbf{C L}_{2}$ showed an average strain at break of $82 \%$, $Y_{10 \%}=462 \mathrm{kPa}$, and a tensile strength of $287 \mathrm{kPa}$, material $\mathbf{E}-\mathbf{C L}_{4}$ showed an average strain at break of 42\%, $Y_{10 \%}=785 \mathrm{kPa}$, and a tensile strength of $290 \mathrm{kPa}$, and $\mathbf{E}-\mathbf{3 . 5 C \mathbf { C L } _ { 4 }}$ showed an average strain at break of 38\%, $Y_{10 \%}=862 \mathrm{kPa}$, and a tensile strength of $304 \mathrm{kPa}$. The mechanical properties of polysiloxane elastomers can be improved by using silica filler. ${ }^{[22]}$ This is also the case for our polar elastomer (Figure S4), when the addition of only $2.5 \mathrm{wt} \%$ of hexamethyldisilazane treated silica particles to $\mathbf{E}-\mathbf{C L}_{2}$ increased the average strain at break to $109 \%{ }^{[22]}$ However, processing composites in very thin films is challenging, since the film thickness may reach the length scale of filler and filler agglomerates and may reduce the dielectric breakdown. Therefore, the addition of filler was avoided in this work. 
Cyclic uniaxial tensile tests at different strain levels (5 cycles for each strain) were conducted (Figure 2b,c). The strain on E-CL2 was successively increased from $25 \%$, to $40 \%$ and to $50 \%$ strain, while for the more fragile sample $\mathbf{E}-\mathbf{C L}_{4}$ the strains used were slightly lower, of $10 \%, 20 \%$ and $25 \%$. Both materials recovered immediately the initial length after the stress was released. The curves showed no hysteresis between loading and unloading, an indication of the excellent elastic properties of these materials. These results are also supported by DMA and electromechanical cyclic tests. Frequency dependence of the storage moduli ( $E$ '), and loss (E”) of $\mathbf{E}-\mathbf{C L}_{2}, \mathbf{E}-\mathbf{C L}_{4}$, and $\mathbf{E}-\mathbf{3 . 5 C} \mathbf{C L}_{4}$ (Figure 2d) are compared to Elastosil@Film 2030 250, a well know polysiloxane-based commercial elastomer used as a reference. At $0.05 \mathrm{~Hz}$ material $\mathbf{E}-\mathbf{C L}_{2}$ has a $E^{\prime}=350 \mathrm{kPa}$ and a $\tan \delta=0.007, \mathbf{E}-\mathbf{C L}_{\mathbf{4}}$ has a $E^{\prime}$ $=665 \mathrm{kPa}$ and a $\tan \delta=0.0027, \mathbf{E}-3.5 \mathbf{C L}_{4}$ has a $E^{\prime}=790 \mathrm{kPa}$ and a $\tan \delta=0.0018$, and the reference material Elastosil has an $E^{\prime}=1.2 \mathrm{MPa}$ and a $\tan \delta=0.017$, respectively. For all materials, the elastic moduli did not change much over the investigated frequency ranges. The mechanical losses of all materials are very low. For Elastosil and $\mathbf{E}-\mathbf{C L}_{\mathbf{4}}$ only a slight increase in the losses over the investigated frequency range was observed. All other materials show a slight increase in $\tan \delta$ with the frequency, but the losses at the investigated frequency range were below 0.13 . Dynamic mechanical analysis conducted at temperatures between $+50{ }^{\circ} \mathrm{C}$ to $-80{ }^{\circ} \mathrm{C}$ and temperature ramping of $-5^{\circ} \mathrm{C}$ shows that these elastomers are glassy below $-50{ }^{\circ} \mathrm{C}$. At this temperature, all samples ruptured during the DMA measurements (Figure 2e). The transition between the glassy and rubbery phase is reflected by the strong increase in the elastic modulus at temperatures below $-20{ }^{\circ} \mathrm{C}$. Above $-0{ }^{\circ} \mathrm{C}$ the storage modulus remains rather constant, which is very attractive for actuators. Differential scanning calorimetry (DSC) revealed a glass transition at about $-46^{\circ} \mathrm{C}$ (Figure S5). No further transitions were observed in the DSC curves, whose slope remains constant up to $50{ }^{\circ} \mathrm{C}$. 
The dielectric properties were investigated at room temperature and different frequencies (Figure 2f) as well as at temperatures ranging from $-80{ }^{\circ} \mathrm{C}$ to $100^{\circ} \mathrm{C}$ (Figure S6). Below $T_{g}$, the nitrile groups are frozen and thus they cannot be oriented in an electric field. Therefore, $\varepsilon^{\prime}$ is rather low below $T_{g}\left(\varepsilon^{\prime}=4.7\right)$. Above $T_{g}$, the polymer chains are mobile and the polar groups are able to orient and thus contribute to the permittivity value by orientation polarization. Consequently, the permittivity of the prepared elastomers increased to $\varepsilon^{\prime} \sim 18$ at $10^{4} \mathrm{~Hz}$ (Figure 2f). Above $T_{g}$, not only the dipoles are able to orient in an electric field, but also the ion impurities with which the materials are unavoidable contaminated. The presence of ion impurities is reflected by the steep increase in permittivity at low frequencies, which is often referred to as electrode polarization. ${ }^{[27]}$ For the synthesis of the three materials the same batch of polymer P1 was used, therefore only slight differences in the permittivity values were observed, which are likely related to error measurements. Two relaxation peaks are present in all materials. One appears at rather low frequencies between 1 and $10 \mathrm{~Hz}$ and is due to ion impurities present in materials, while the other appears above $10^{6} \mathrm{~Hz}$ and is due to the relaxation of the polar nitrile groups. ${ }^{[25]}$ The conductivity of all materials was rather low, below $3.2 \times 10^{-9} \mathrm{~S} \mathrm{~cm}^{-1}$ which is also attractive for actuators. 


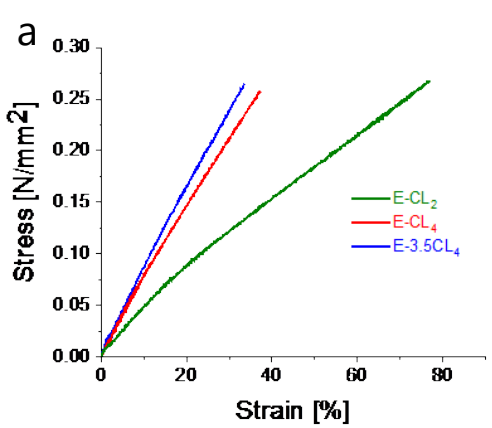

d

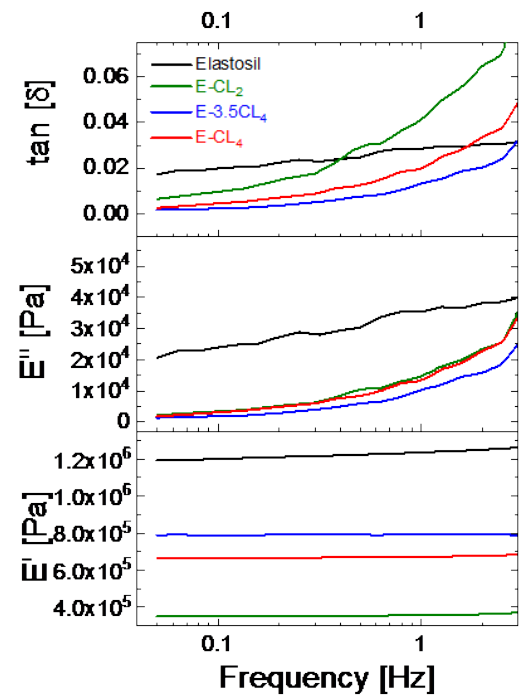

b

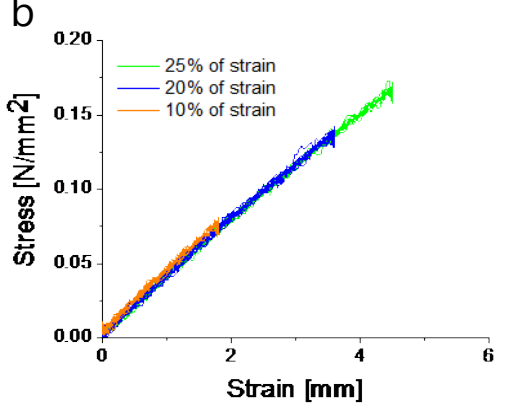

e

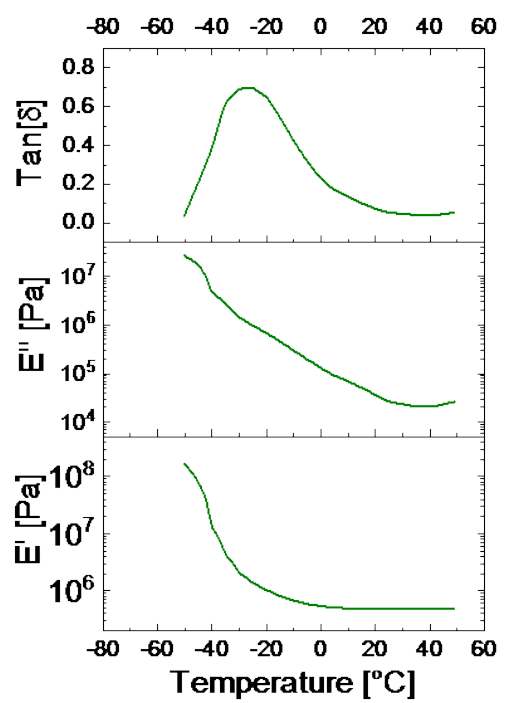

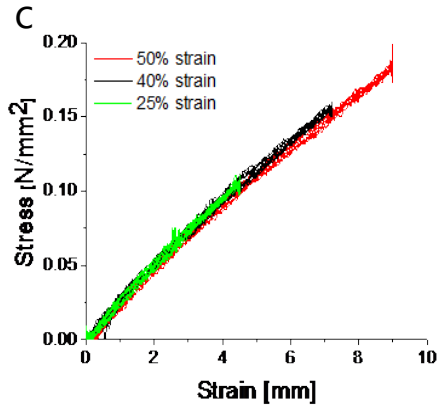

$f$

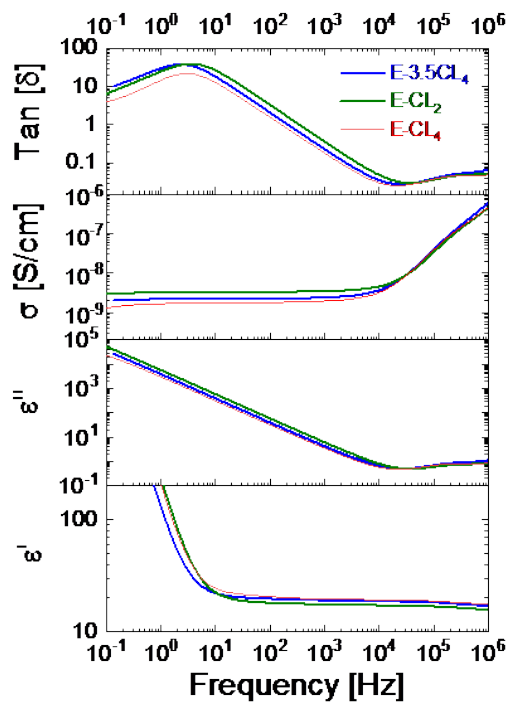

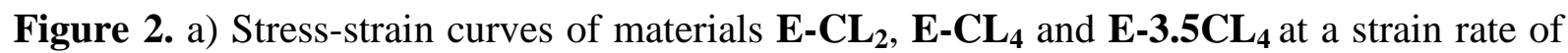
$50 \mathrm{~mm} / \mathrm{min}$. b) Cyclic uniaxial tensile tests of $\mathbf{E}-\mathbf{C L}_{4}$ at $10 \%, 20 \%$, and $25 \%$ strain. c) Cyclic uniaxial tensile tests of $\mathbf{E}-\mathbf{C L}_{2}$ at 25\%, 40\%, and 50\% strain. d) Dynamic mechanical analysis of E-CL $\mathbf{C L}_{2}, \mathbf{E}-\mathbf{C L}_{4}, \mathbf{E}-\mathbf{3 . 5 C \mathbf { C L } _ { 4 }}$ and Elastosil at $\%$ strain and a frequency range between 0.05 to $3 \mathrm{~Hz}$. e) Dynamic mechanical analysis at different temperatures and $1 \mathrm{~Hz}$ for $\mathbf{E}-\mathbf{C L}_{\mathbf{2}}$. f) Dielectric properties (permittivity, dielectric loss, conductivity, and loss factor) as a function of frequency for $\mathbf{E}-\mathbf{C L}_{2}, \mathbf{E}-\mathbf{C L}_{4}, \mathbf{E}-3.5 \mathbf{C L}_{4}$.

Electromechanical tests conducted on circular actuators showed that actuation with these materials was possible at rather low electric fields, but the driving voltage above $1000 \mathrm{~V}$ was still rather high. An actuator constructed from a $109 \mu$ m thick film of $\mathbf{E}-\mathbf{C L}_{\mathbf{4}}$ was actuated at an electric field of $10 \mathrm{~V} / \mu \mathrm{m}$, thus $1090 \mathrm{~V}$, and at different frequencies of $0.25 \mathrm{~Hz}, 0.5 \mathrm{~Hz}, 1$ $\mathrm{Hz}, 2 \mathrm{~Hz}, 5 \mathrm{~Hz}$, and $10 \mathrm{~Hz}$, respectively, and showed a stable actuation, which supports excellent elasticity (Figure S7). At frequencies between $0.25 \mathrm{~Hz}$ to $2 \mathrm{~Hz}$ the actuation strain remained almost unchanged of 3.5\% at $10 \mathrm{~V} / \mu \mathrm{m}$. However, when increasing the frequency to 
$5 \mathrm{~Hz}$, the actuation decreased to about 2.5\% strain at the same electric field. Although the actuator was tested also at $10 \mathrm{~Hz}$ for 100 cycles, the actuation measurement is not precise, because of the limitation of the camera used. Long term measurements of over 10000 cycles clearly support that the prepared materials are rather robust (Figure S8 and Video S1).

To demonstrate that actuators operable at lower voltages can be constructed with our materials, very thin films had to be prepared and manipulated. A special process was developed that allowed us manipulating thin films (Figure 3a). To avoid mechanical peeling the films off the substrate, sacrificial polyvinyl alcohol (PVA) layer was used. ${ }^{[28]}$ Sacrificial layer was previously used for the formation of thin polymer films and has recently been introduced to actuator technology. ${ }^{[29]}$ After depositing a thin PVA layer on a glass substrate, a film of our material was formed on top and cross-linked by UV irradiation. Thereafter, the two layers were detached from the glass substrate. Part of the film was cut and fixed between two plastic frames and immersed in a water bath to dissolve the PVA. Using this procedure, any mechanical stress on the film was avoided and films with a thickness around $20 \mu \mathrm{m}$ could be investigated. No further attempts were conducted to reduce the thickness of the films even further, but this should in principle be possible. 


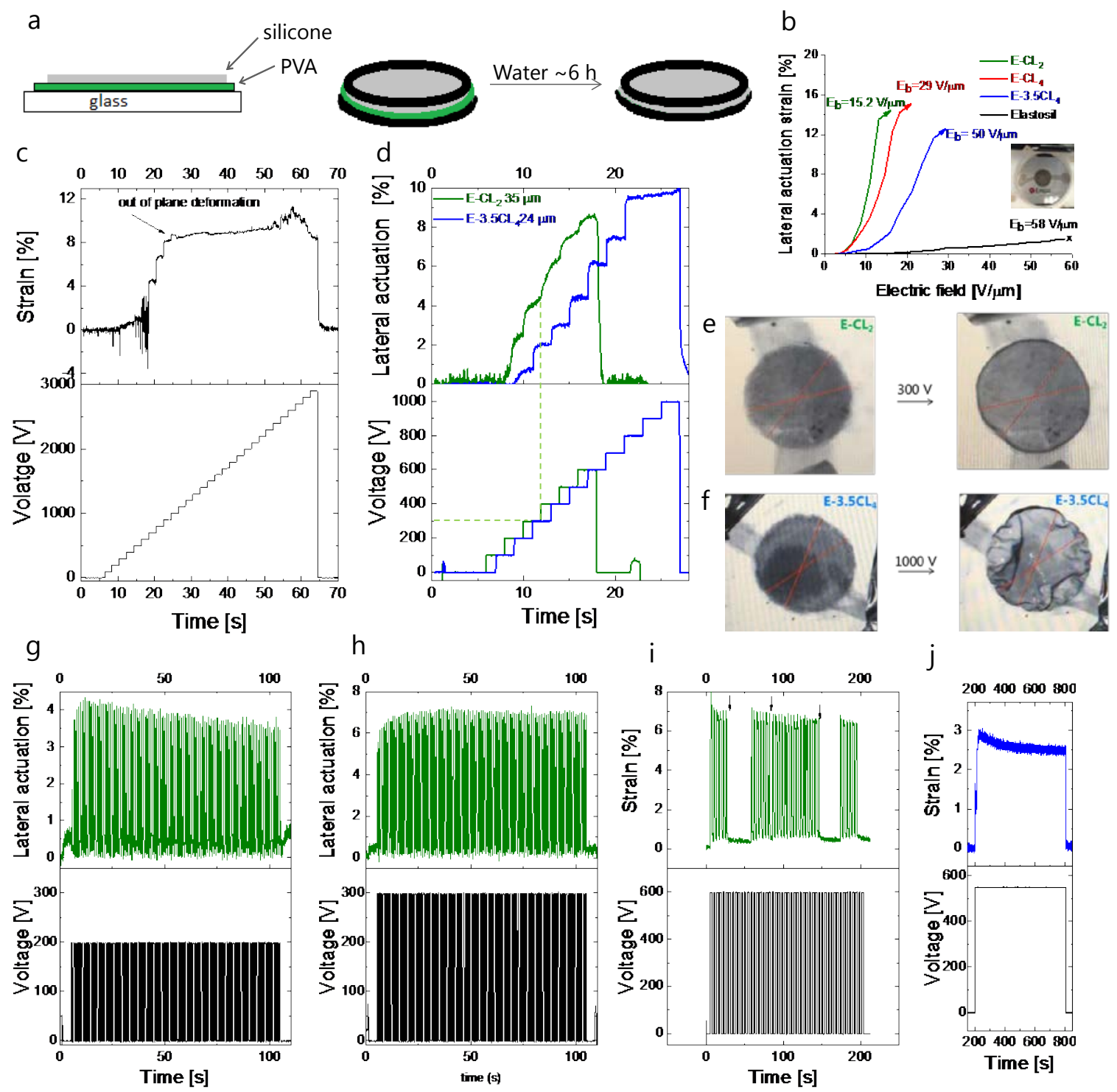

Figure 3. a) Illustration of the process used for preparation and manipulation of very thin films. b) Lateral actuation strain as a function of electric field for circular actuators constructed from thin films of E-CL $2, \mathbf{E}-\mathbf{C L}_{4}, \mathbf{E}-\mathbf{3 . 5} \mathbf{C L}_{4}$, and Elastosil and insert a photograph of the transparent silicone film of $\mathbf{E}-\mathbf{C L}_{2}$ with a thickness of about $20 \mu \mathrm{m}$ from which a circular actuator was constructed. c) An actuator constructed from a $38 \mu \mathrm{m}$ thick E3.5CL $\mathrm{CL}_{4}$ films that withstood electric fields as high as $100 \mathrm{~V} / \mu \mathrm{m}$. d) Lateral actuation strain at different voltages for an actuator constructed from E-CL $\mathbf{C L}_{2}(35 \mu \mathrm{m})$ and from E-3.5CL $\mathbf{C}_{\mathbf{4}}(24$ $\mu \mathrm{m})$. Out of plane deformation was observed for $\mathbf{E}-\mathbf{3 . 5 C \mathbf { C L } _ { 4 }}$ at voltages above $500 \mathrm{~V}$. e) Photographs of actuators constructed from $\mathbf{E}-\mathbf{C L}_{2}$ in the relaxed state and in actuated state at $300 \mathrm{~V}(\mathrm{E}=8.6 \mathrm{~V} / \mu \mathrm{m})$. f) Photographs of actuators constructed from $\mathbf{E}-\mathbf{3 . 5 C \mathbf { C L } _ { 4 }}$ in the relaxed state and in actuated state at $1000 \mathrm{~V}(\mathrm{E}=41 \mathrm{~V} / \mu \mathrm{m})$ with large out of plane deformation. $\mathrm{g})$ Cyclic tests conducted on an actuator constructed from $\mathbf{E}-\mathbf{C L}_{2}(35 \mu \mathrm{m})$ at $200 \mathrm{~V}$ and $\left.1 \mathrm{~Hz} . \mathrm{h}\right)$ Cyclic tests conducted on an actuator constructed from $\mathbf{E}-\mathbf{C L}_{2}(35 \mu \mathrm{m})$ at $300 \mathrm{~V}$ and $1 \mathrm{~Hz}$. i) An actuator constructed from E-CL $\mathbf{C L}_{2}(43 \mu \mathrm{m})$ actuated at $600 \mathrm{~V}$, where three dielectric breakdown events indicated by the arrows, followed by self-reparation events can be seen. $\mathrm{j}$ ) Stable lateral actuation of $\mathbf{E}-\mathbf{C L}_{4}(55 \mu \mathrm{m})$ at $10 \mathrm{~V} / \mu \mathrm{m}$ for $600 \mathrm{~s}$. 
Next, circular actuators with electrodes diameter of $8 \mathrm{~mm}$ made of carbon black powder were constructed. Figure 3b shows the lateral actuation strain as function of nominal electric field for the three new materials developed as well as for Elastosil silicone film, a well-known material to the DEAs community. It should be mentioned that due to the lack of prestrain in actuators, the lateral actuation stain was precisely measured only up to a certain electric field. Above this electric field, expansion in the lateral direction is hindered and wrinkles and out of plane actuation were noted. The onset for this process is indicated in Figure $3 \mathrm{~b}$ on the actuation curves by the arrows. The best actuators constructed from $\mathbf{E}-\mathbf{C L}_{\mathbf{2}}, \mathbf{E}-\mathbf{C L}_{4}$, and $\mathbf{E}$ 3.5CL $\mathrm{CL}_{4}$ showed a lateral actuation of $13 \%$ at $13 \mathrm{~V} / \mu \mathrm{m}$, of $14 \%$ at $18 \mathrm{~V} / \mu \mathrm{m}$, and of $11.5 \%$ at $26 \mathrm{~V} / \mu \mathrm{m}$, respectively. Thus high actuations at rather low electric fields were demonstrated with these actuators. Contrary, Elastosil ( $\varepsilon^{\prime} \sim 3$ ), shows only a very small actuation below $1 \%$ at comparable electric fields. The nominal dielectric breakdown, calculated using the breakdown voltage divided by the initial thickness for these actuators was $15.2 \mathrm{~V} / \mu \mathrm{m}, 29$ $\mathrm{V} / \mu \mathrm{m}$, and $50 \mathrm{~V} / \mu \mathrm{m}$ for $\mathbf{E}-\mathbf{C L}_{2}, \mathbf{E}-\mathbf{C L}_{\mathbf{4}}$, and $\mathbf{E}-\mathbf{3 . 5} \mathbf{C L}_{\mathbf{4}}$, respectively, whereas the dielectric breakdown of Elastosil was $58 \mathrm{~V} / \mu \mathrm{m}$. It should be said that not all actuators performed equally well, although all showed actuation at very low voltages (Figure S9 and Video S2). We identified three reasons that may explain this deviation: film defects, presence of residual PVA on the films surface, and measurement error. At least five actuators were evaluated for each material. Actuators' average $E_{b}$ was $19 \mathrm{~V} / \mu \mathrm{m}$ for $\mathbf{E}-\mathbf{C L}_{2}, 25.5 \mathrm{~V} / \mu \mathrm{m} \mathbf{E}-\mathbf{C L}_{4}$, and 73.6 $\mathrm{V} / \mu \mathrm{m} \mathbf{E}-3.5 \mathbf{C L}_{4}$ for thin films, and decreased to $16 \mathrm{~V} / \mu \mathrm{m}$ for $\mathbf{E}-\mathbf{C L}_{2}, 22.7 \mathrm{~V} / \mu \mathrm{m} \mathbf{E}-\mathbf{C L}_{4}$, and

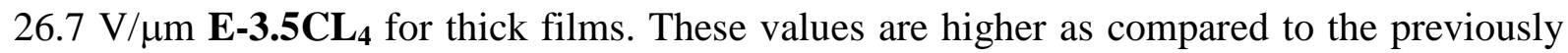
reported one of $15.6 \mathrm{~V} \mu \mathrm{m}^{-1}$ for a material with similar chemical composition. ${ }^{[22,23]}$ The reason behind this increase is seen in the higher purity of the prepolymer used, in the increased elastic modulus of the new materials, and in the improved processability in thin films. The much higher $E_{b}$ of $\mathbf{E}-\mathbf{3 . 5 C} \mathbf{L}_{4}$ as compared to $\mathbf{E}-\mathbf{C L}_{2}$ and $\mathbf{E}-\mathbf{C L}_{\mathbf{4}}$ is explained by the lower 
elastic modulus of the latter. For E-3.5CL $\mathbf{L}_{4}$ the $E_{b}$ of thick and thin actuators differ significantly, e.g., the $E_{b}$ increased from $26.7 \mathrm{~V} / \mu \mathrm{m}$ for thick films to an average of 73.6 $\mathrm{V} / \mu \mathrm{m}$ for thin one. Some devices withstood electric fields up to $100 \mathrm{~V} / \mu \mathrm{m}$, where large out of plane actuation occurred (Figure 3c and Video S3). Large actuations have been reported before, but because the elastomers used had a low dielectric permittivity, actuation occurred at significantly higher voltages. ${ }^{[1,30-37]}$ The high $E_{b}$ observed in this material may be explained by the lower probability of defects present in thin films. Whether or not the polarization saturation plays a role in overcoming the snap-through instability by altering the voltagestretch curve, as suggested by Suo's et al. in theoretical studies, needs more investigations. ${ }^{38}$ Furthermore, the leakage current density of all materials was as low as $0.5 \mu \mathrm{A} / \mathrm{cm}^{2}$ and increased slightly when approaching the dielectric breakdown (Video S4).

To demonstrate that actuation at very low voltages is possible, Figure 3d shows the lateral actuation at increasing voltages for $\mathbf{E}-\mathbf{C L}_{2}$ and $\mathbf{E}-\mathbf{3 . 5} \mathbf{C L}_{\mathbf{4}}$. Both actuators respond to voltages as low as $300 \mathrm{~V}$ and the actuation strain increases with increasing voltage. Video S5,6 in the Supporting Information shows actuation of these materials at different voltages. Figures 3e,f show photographs of two actuators while being actuated: $\mathbf{E}-\mathbf{C L}_{2}(35 \mu \mathrm{m})$ at 300 $\mathrm{V}$ and $\mathbf{E}-3.5 \mathbf{C L}_{4}(24 \mu \mathrm{m})$ at $1000 \mathrm{~V}$. In the latter, a huge out of plane deformation can be seen. It is important to note that despite the rather low strain at break measured for $\mathbf{E - 3 . 5 C} \mathbf{C L}_{\mathbf{4}}$ in the tensile test, none of the actuators suffered mechanical failure despite their huge actuation (Figure 3f). Why the elastic network is mechanically more resistant under electrical stress needs further investigations.

Figure 3g,h shows the long term actuation of a device constructed from $\mathbf{E}-\mathbf{C L}_{2}$ exhibiting 4\% and 7\% actuation at $200 \mathrm{~V}$ and $300 \mathrm{~V}$, respectively, for 100 cycles at $1 \mathrm{~Hz}$ (see Video S7). Another actuator constructed from E-CL2 showed $9.7 \%$ actuation strain at $400 \mathrm{~V}$ (Figure S10). The actuator constructed from $\mathbf{E}-\mathbf{C L}_{2}$ had a thickness of $35 \mu \mathrm{m}$ and actuated at 
$200 \mathrm{~V}$, a value which is extremely low in dielectric elastomer actuators. While, low voltage dielectric elastomer actuators were demonstrated before with a $1.4 \mu \mathrm{m}$ thick regular silicone film, which actuated at $100 \mathrm{~V},{ }^{[13]}$ our materials actuated at similar voltages, although more than ten times thicker films were used. The thrilling aspect of our materials is, that further reduction of film thickness should enable to reduce the driving voltage even further, possibly into a range where application in human bodies comes into reach.

Additionally, our devices were able to self-repair after a breakdown, which is quite advantageous as this increases actuator's reliability and lifetime. Figure $3 \mathrm{i}$ shows an actuator operated at $600 \mathrm{~V}$ for 50 cycles at $0.25 \mathrm{~Hz}$. Three dielectric breakdown events followed by self-reparation events can be seen. After self-reparation, only a very small decrease in actuation performance was noted. Self-reparation of actuators has been reported before and it was either due to electrode material which degraded at the breakdown site or due to flowing of plasticizer into defects. ${ }^{[39-42]}$ In this case, the self-reparation of the actuators is due to combustion of the conductive path. During electrical breakdown, the small spark produced burns part of the electrode and thus insulates the conductive path. An actuator subjected to $600 \mathrm{~V}$ for $600 \mathrm{~s}$ demonstrated the material to have low creep and very fast strain recovery (Figure 3j).

\section{Conclusion}

In conclusion, we have developed new dielectric elastomer materials based on nitrile modified silicone for which the mechanical properties can be easily tuned by the type and content of cross-linker used. The elastomers have a dielectric permittivity of 18 and a low leakage current density of $0.5 \mu \mathrm{A} / \mathrm{cm}^{2}$, which slightly increases only when approaching the dielectric breakdown. We describe how to create and manipulate films with a thickness of down to 20 $\mu \mathrm{m}$, which makes our elastomers unmatched in terms of high permittivity in thin elastomeric films. We constructed actuators operable at unprecedentedly low voltages of $200 \mathrm{~V}$ and 
reproducibly observed the films to efficiently self-repair after a breakdown. Self-repair is key to long actuator lifetimes and high reliability. The stiffer actuators withstand electric fields up to $100 \mathrm{~V} / \mu \mathrm{m}$. This is rather high for soft elastomers with a dielectric permittivity value of 18 and suggests their applicability to actuators that can generate high electrostatic forces. With this unprecedented property combination our materials are not only attractive for simple actuators, but also promise to be applicable for stacked actuators. Such devices are composed of many thin actuator layers stacked on top of each other and will be constructed next to exploit the full potential of our materials. In parallel we will additionally reduce the film thickness even further to reduce the driving voltage into a range (approx. $40 \mathrm{~V}$ ) required to in vivo applications.

\section{Experimental Section}

\section{Materials}

Unless otherwise stated, all chemicals were reagent grade and used without purification. 1,3,5,7-tetramethyl-1,3,5,7-tetravinyl cyclotetrasiloxane $\left(\mathrm{V}_{4}\right)$ was purchased from ABCR. 2,2Dimethoxy-2-phenylacetophenone (DMPA), 2,2'-(ethylenedioxy)diethanethiol, benzene, toluene, 3-chloropropionitril, tetramethylammonium hydroxide 25\% in $\mathrm{MeOH}$ (TMAH), and thiourea were purchased from Aldrich. Methanol and tetrahydrofuran were purchased from VWR. An as received solution of PVA in isopropanol/2-butanol from Suter Kunststoffe AG was used as sacrificial layer. Elastosil films with a thickness of $200 \mu \mathrm{m}$ were purchased from Wacker. Polymethylvinylsiloxane $\left(\mathrm{M}_{n}=87800 \mathrm{Da}, \mathrm{M}_{w}=200000 \mathrm{Da}, \mathrm{PDI}=2.3\right)$ and 3mercaptoproprionitrile were prepared according to the literature. ${ }^{[22]}$

\section{Characterization}

${ }^{1} \mathrm{H}$ and ${ }^{13} \mathrm{C}$ NMR spectra were recorded at $298 \mathrm{~K}$ on a Bruker Avance 400 NMR spectrometer using a $5 \mathrm{~mm}$ broadband inverse probe at 400.13 and $100.61 \mathrm{MHz}$, respectively. Chemical shifts $(\delta)$ in ppm are calibrated to residual solvent peaks $\left(\mathrm{CDCl}_{3}: \delta=7.26\right.$ and $\left.77.16 \mathrm{ppm}\right)$. Size exclusion chromatograms were taken with an Agilent 1100 Series HPLC (Columns: 
serial coupled PSS SDV $5 \mu \mathrm{m}, 100 \AA \AA$ and PSS SDV $5 \mu \mathrm{m}, 1000 \AA$, Detector: DAD, 235 nm and $360 \mathrm{~nm}$; refractive index), with THF as mobile phase. PDMS standards were used for the calibration and toluene as internal standard.

As UV source a lamp from Peschl Ultraviole SwiftCure HL-250 ( 35 mW cm-2) placed at $20 \mathrm{~cm}$ distance from the film was used.

Differential scanning calorimetry (DSC) investigations were undertaken on a Perkin Elmer Pyris Diamond DSC instrument. Two heating and one cooling steps with a heating and cooling rate of $20{ }^{\circ} \mathrm{C} \mathrm{min}^{-1}$ in the temperature range of $-90{ }^{\circ} \mathrm{C}$ to $50{ }^{\circ} \mathrm{C}$ were conducted per measurement under a nitrogen flow $\left(50 \mathrm{ml} \mathrm{min}^{-1}\right)$. The second heating step was considered for the evaluation of the $T_{g}$. About $10 \mathrm{mg}$ sample was weighted in aluminum crucibles shut with pierced lids.

The tensile tests and the cyclic uniaxial tensile stress tests were performed on a Zwick Z010 tensile test machine with a crosshead speed of $50 \mathrm{~mm} / \mathrm{min}(278 \% / \mathrm{min})$. Tensile test specimens with a gauge width of $2 \mathrm{~mm}$ and a gauge length of $18 \mathrm{~mm}$ were prepared by die cutting. The strain was determined over the traverse moving sensor. The curves were averaged from 3 different samples per material. The tensile modulus was determined from the slope of the stress-strain curves using a linear fit to the data points within $10 \%$ strain.

Dynamic mechanical analysis was carried out on a RSA 3 DMA from TA Instruments. Stripes of $10 \mathrm{~mm} \times 20 \mathrm{~mm}$ were measured under a dynamic load of $2.5 \mathrm{~g}$, at $2 \%$ strain in the frequency range of $0.05-3 \mathrm{~Hz}$ at $25{ }^{\circ} \mathrm{C}$ and $65 \%$ humidity. Dynamic mechanical analysis at temperatures between $-50{ }^{\circ} \mathrm{C}$ to $50^{\circ} \mathrm{C}$ was conducted on a RSA 3 DMA from TA Instruments. Stripes of $10 \mathrm{~mm} \times 20 \mathrm{~mm}$ were measured at a frequency of $1 \mathrm{~Hz}$ under a dynamic load of $2 \mathrm{~g}$ at $2 \%$ strain. The measurements were started at $50{ }^{\circ} \mathrm{C}$ and the samples were tested from $50{ }^{\circ} \mathrm{C}$ down to $-50{ }^{\circ} \mathrm{C}$ in $5{ }^{\circ} \mathrm{C}$ interval.

Permittivity measurements were done in the frequency range of $0.1 \mathrm{~Hz}$ to $1 \mathrm{MHz}$ using a Novocontrol Alpha-A Frequency Analyzer. The $\mathrm{V}_{\mathrm{RMS}}$ (root mean square voltage) of the 
probing AC electric signal applied to the samples was $1 \mathrm{~V}$. The samples were squeezed between two electrodes (diameter of $20 \mathrm{~mm}$ ).

Circular electrodes (8 mm diameter) of carbon black powder were applied to each side of the film. A FUG HCL-35-12500 high voltage source served as power supply for actuator tests. The voltage was increased by $100 \mathrm{~V}$ steps every $2 \mathrm{~s}$ up to breakdown. The actuation strain was measured optically as the extension of the diameter of the electrode area via a digital camera, using an edge detection tool of a LabView program to detect the boundary between the black electrode area and the transparent silicone film.

Synthesis of poly(3-ethylsulfanyl propionitrile methyl-co-methylvinyl)siloxane (P1)

To a solution of polymethylvinylsiloxane (20 g, $0.232 \mathrm{~mol}, 1 \mathrm{eq})$ in distilled THF (600 ml), DMPA (564 mg, 0.009 eq) and 2-cyanoethylthiol (19.2 g, $0.220 \mathrm{~mol}, 0.95$ eq) were added. The reaction mixture was degassed three times using the freeze-pump-thaw technique and irradiated for 20 min with a UV light. Then, it was concentrated at a rotary evaporator to about one third of the initial volume and the functionalized polymer was precipitated in methanol. This purification procedure was repeated four times by dissolution/precipitation in THF/methanol. The polymer was only slightly dried in order to avoid unwanted polymer crosslinking. It was then dissolved in THF, and the solvent was distilled off once more in order to remove more of the residual methanol. This process was repeated few times and then the final concentration of the polymer solution in THF was adjusted to $40 \mathrm{wt} \%$. A yellowish transparent solution was obtained.

Formation of thin films

A solution of PVA in isopropanol and butanol was cast on a glass plate and dried. On top of the PVA layer, a solution of 40 wt $\% \mathbf{P 1}$ in THF, the cross-linker (see Table 1), and DMPA was cast in thin films by doctor blade technique. The films were let to stand at room temperature for 60 min and were then cross-linked by irradiating with UV light. The PVA layer on which the silicone film was cross-linked was easily removed from the glass substrate. 
The necessary film shape for actuator construction was cut, fixed between two circular plastic frames and put into water for $6 \mathrm{~h}$ at $50{ }^{\circ} \mathrm{C}$. During this time, the PVA sacrificial layer was dissolved. All samples after crosslinking were dried under reduced pressure at $60^{\circ} \mathrm{C}$ for $24 \mathrm{~h}$. Using this procedure, very thin actuators were prepared and their actuation performance could be tested. Some of the characteristics of the prepared materials are summarized in Table 2.

Table 1. The amount of reagents used for the synthesis of thin films.

\begin{tabular}{|c|c|c|c|c|}
\hline Sample & CL $[\mu l]^{a)}$ & $\mathrm{mmol} \mathrm{CL}$ & THF $[g]^{\text {a) }}$ & DMPA [mg] $]^{\text {a) }}$ \\
\hline $\mathrm{E}-\mathrm{CL}_{2}$ & $\mathrm{CL}_{2}[5]$ & 0.0307 & 1.5 & 5 \\
\hline $\mathrm{E}-\mathrm{CL}_{4}$ & $\mathrm{CL}_{4}[5.7]$ & 0.015 & 1.5 & 5 \\
\hline $\mathrm{E}-3.5 \mathrm{CL}_{4}$ & $\mathrm{CL}_{4}[20]$ & 0.0525 & 1.5 & 5 \\
\hline
\end{tabular}

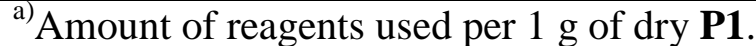

Table 2. The mechanical and dielectric characteristics of the three different materials developed.

\begin{tabular}{|c|c|c|c|c|c|c|c|c|}
\hline Material & $\begin{array}{c}\mathrm{s}^{\mathrm{a}} \\
{[\%]}\end{array}$ & $\begin{array}{l}\mathrm{Y}_{10 \%} \\
{[\mathrm{kPa}]}\end{array}$ & $\begin{array}{l}\text { Max. stress } \\
{[\mathrm{kPa}]}\end{array}$ & $\begin{array}{l}\mathrm{E}^{\prime \prime} @ \\
{[\mathrm{kPa}]}\end{array}$ & $\tan \delta^{b}$ & $\begin{array}{l}\mathrm{E}_{\mathrm{b}} \text { thin }^{\mathrm{C}} \\
{[\mathrm{V} / \mu \mathrm{m}]}\end{array}$ & $\begin{array}{c}\mathrm{E}_{\mathrm{b}} \text { thick }^{\mathrm{C}} \\
{[\mathrm{V} / \mu \mathrm{m}]}\end{array}$ & $\begin{array}{l}\mathrm{S}_{\mathrm{z}}{ }^{\mathrm{d}} \\
{[\%]}\end{array}$ \\
\hline $\mathrm{E}-\mathrm{CL}_{2}$ & 82 & 462 & 287 & 350 & 0.007 & 19 & 16 & 13@13 V/ $/ \mu \mathrm{m}$ \\
\hline $\mathrm{E}-\mathrm{CL}_{4}$ & 42 & 785 & 290 & 665 & 0.0027 & 25.5 & 22.7 & 14@18 V/ $/ \mu \mathrm{m}$ \\
\hline E-3.5CL 4 & 38 & 862 & 304 & 790 & 0.0018 & 73.6 & 26.7 & 11.5@26 V/ $\mu \mathrm{m}$ \\
\hline
\end{tabular}

${ }^{a}$ Average strain at break, ${ }^{b}$ measured at $0.05 \mathrm{~Hz}$, ${ }^{\mathrm{c}}$ electrical breakdown of thin $(<55 \mu \mathrm{m})$ and thick films measured (100 $\mu \mathrm{m}$ to $130 \mu \mathrm{m})$ during the actuator tests, ${ }^{\mathrm{d}}$ lateral actuation strain at a certain electric field of the best actuators.

\section{Supporting Information}

Supporting Information is available from the Wiley Online Library or from the author.

\section{Acknowledgements}

We gratefully acknowledge Swiss National Science Foundation (IZERZO_142215 and 200020_172693) and Swiss Federal Laboratories for Materials Science and Technology (Empa, Dübendorf) for financial support. We also acknowledge B. Fischer (Empa) for DSC and TGA measurements, Dr. G. Kovacs (Empa), Prof. H. Frauenrath (EPFL), and Prof. A. Kilbinger (University of Fribourg) for their kind support. We also thank Prof. F. A. Nüesch for his continuous and generous support.

Received: ((will be filled in by the editorial staff)) Revised: ((will be filled in by the editorial staff)) Published online: ((will be filled in by the editorial staff)) 
References

[1] R. Pelrine, R. Kornbluh, Q. Pei, J. Joseph, Science 2000, 287, 836-839.

[2] P. Brochu, Q. Pei, Macromol. Rapid Commun. 2010, 31, 10-36.

[3] I. A. Anderson, T. A. Gisby, T. G. McKay, B. M. O’Brien, E. P. Calius, J. Appl. Phys. 2012, 112, 041101.

[4] B. Müller, H. Deyhle, S. Mushkolaj, M. Wieland, Swiss Med. Wkly. 2009, 139, 6.

[5] J. Biggs, K. Danielmeier, J. Hitzbleck, J. Krause, T. Kridl, S. Nowak, E. Orselli, X.

Quan, D. Schapeler,W. Sutherland, J. Wagner, Angew. Chem. Int. Ed. 2013, 52, 9409W.

[6] Q. M. Zhang, M. J. Serpe, ChemPhysChem, 2017, 18, 1 - 16.

[7] F. B.Madsen, A. E. Daugaard, S. Hvilsted, A. L. Skov, Macromol. Rapid Commun. 2016, 37, 378-413.

[8] D. M. Opris, Adv. Mater. 2018, 30, 1703678.

[9] L.J. Romasanta, M.A. Lopez-Manchado, R. Verdejo, Prog. Polym. Sci. 2015, 51, 188.

[10] I. Burda, C. Baechler, S. Gardin, A. Verma, G.P. Terrasi, G. Kovacs, Sens. Actuators A 2018, 279, 712-724.

[11] R. E. Perline, R. D. Kornbluh, J. P. Joseph, Sens. Actuators A 1998, 64, 77.

[12] A. Poulin, S. Rosset, H. R. Shea, Appl. Phys. Lett. 2015, 107, 244104.

[13] X. Ji, A. E. Haitami, F. Sorba, S. Rosset, G. T.M. Nguyen, C. Plesseb, F. Vidal, H. R. Shea, S. Cantin, Sens. Actuators, B, 2018, 261, 135-143.

[14] G. Kovacs, 2014, CH 706837 A1 20140228.

[15] D. M. Opris, M. Molberg, C. Walder, Y. S. Ko, B. Fischer, F. A. Nüesch, Adv. Funct. Mater. 2011, 21, 3531.

[16] Y. Jang, T. Hirai, T. Uekia, T. Kato, Polym. Int. 2012, 61, 228.

[17] A. G. Bejenariu, L. Yu, A. L. Skov, Soft Matter 2012, 8, 3917. 
[18] M. Vatankhah-Varnoosfaderani, W. F. M. Daniel, A. P. Zhushma, Q. Li, B. J. Morgan, K. Matyjaszewski, D. P. Armstrong, R. J. Spontak, A. V. Dobrynin, S. S. Sheiko, Adv. Mater. 2017, 29, 1604209.

[19] X. Zhao, Z. Suo, Phys. Rev. Lett. 2010, 104, 178302.

[20] X. Niu, H. Stoyanov, W. Hu, R. Leo, P. Brochu, Q. Pei, J. Polym. Sci., Part B: Polym. Phys. 2013, 51, 197.

[21] P. Brochu, H. Stoyanov, X. Niu, Q. Pei, Smart Mater. Struct. 2013, 22, 055022.

[22] S. J. Dünki, Y. S. Ko, F. A. Nüesch, D. M. Opris, Adv. Funct. Mater. 2015, 25, 2467.

[23] S. J. Dünki, F. A. Nüesch, D. M. Opris, J. Mater. Chem. C 2016, 4, 10545.

[24] S. J. Dünki, E. Cuervo-Reyes, D. M. Opris, Polym. Chem. 2017, 8, 715.

[25] S. J. Dünki, M. Tress, F. Kremer, S. Y. Ko, F. A. Nüesch, C.-D. Varganici, C. Racles, D. M. Opris, RSC Adv. 2015, 5, 50054.

[26] Z. Chen, D. C. Webster, Polymer 2006, 47, 3715-3726.

[27] F. Kremer, A. Schönhals, Broadband Dielectric Spectroscopy, Springer, 2003.

[28] A. Komp, J. Rühe, H. Finkelmann, Macromol. Rapid Commun. 2005, 26, 813-818.

[29] S. Rosset, A. Araromi, S. Schlatter, H. Shea, JoVE, 2016, 108, e53423.

[30] S. M. Ha, W. Yuan, Q. Pei, R. Pelrine, S. Stanford, Adv. Mater. 2006, 18, 887-891

[31] R. Shankar, T. K. Ghosh, R. J. Spontak, Adv. Mater. 2007, 19, 2218-2223

[32] C. Keplinger, M. Kaltenbrunner, N. Arnold, S. Bauer, PNAS, 2010, 107, 4505-4510.

[33] J. Huang, T. Li, C. C. Foo, J. Zhu, D. R. Clarke, Z. Suo, Appl. Phys. Lett. 2012, 100, 041911.

[34] P Brochu, H Stoyanov, X Niu and Q Pei, Smart Mater. Struct. 2013, 22, 055022.

[35] X. Niu, H. Stoyanov, W. Hu, R. Leo, P. Brochu, Q. Pei, J. Polym. Sci. B: Polym. Phys. 2013, 51, 197-206. 
[36] M. Vatankhah-Varnoosfaderani, W. F. M. Daniel, A. P. Zhushma, Q. Li, B. J.

Morgan, K. Matyjaszewski, D. P. Armstrong, R. J. Spontak, A. V. Dobrynin, S. S. Sheiko, Adv. Mater. 2017, 29, 1604209.

[37] P. Caspari, S. J. Dünki, F. A. Nüesch, D. M. Opris, J. Mater. Chem. C 2018, 6, 20432053.

[38] B. Li, L. Liu, Z. Suo, Int. J. Smart Nano Mater. 2011, 2, 59-67.

[39] W. Yuan, L. Hu, Z. Yu, T. Lam, J. Biggs, S. M. Ha, D. Xi, B. Chen, M. K. Senesky, G.

Grüner, Q. Pei, Adv. Mater. 2008, 20, 621-625.

[40] S. Michel, B. T. T. Chu, S. Grimm, F. A. Nüesch, A. Borgschulte, D. M. Opris, J. Mater. Chem. 2012, 22, 20736-20741.

[41] S. Hunt, T. G. McKay, I. A. Anderson, Appl. Phys. Lett. 2014, 104, 113701.

[42] Y. Zhang, C. Ellingford, R. Zhang, J. Roscow, M. Hopkins, P. Keogh, T. McNally, C.

Bowen, C. Wan, Adv. Funct. Mater. 2019, 1808431. 


\section{Supporting Information}

\section{Artificial muscles: dielectric elastomers responsive to low voltages}

Yauhen Sheima, Philip Caspari, and Dorina M. Opris*

Y. Sheima, P. Caspari, Dr. D. M. Opris

Swiss Federal Laboratories for Materials Science and Technology Empa, Laboratory for Functional Polymers, Ueberlandstr. 129, CH-8600, Dübendorf, Switzerland

E-mail: dorina.opris@empa.ch

Y. Sheima, P. Caspari

Ecole Polytechnique Fédérale de Lausanne (EPFL), Institut des matériaux, Station 12, CH 1015, Lausanne, Switzerland

\section{C (40wt\% in THF)}
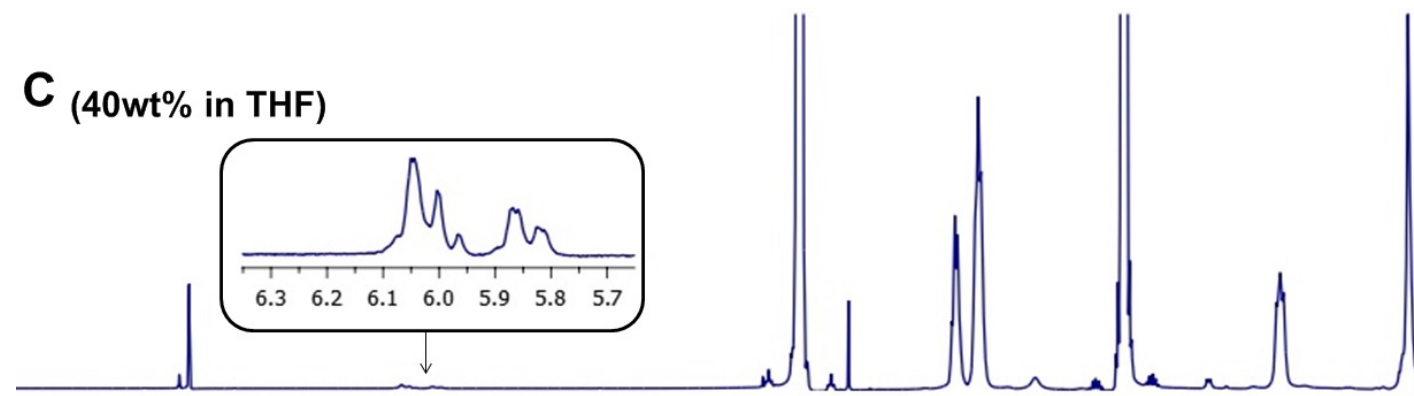

B
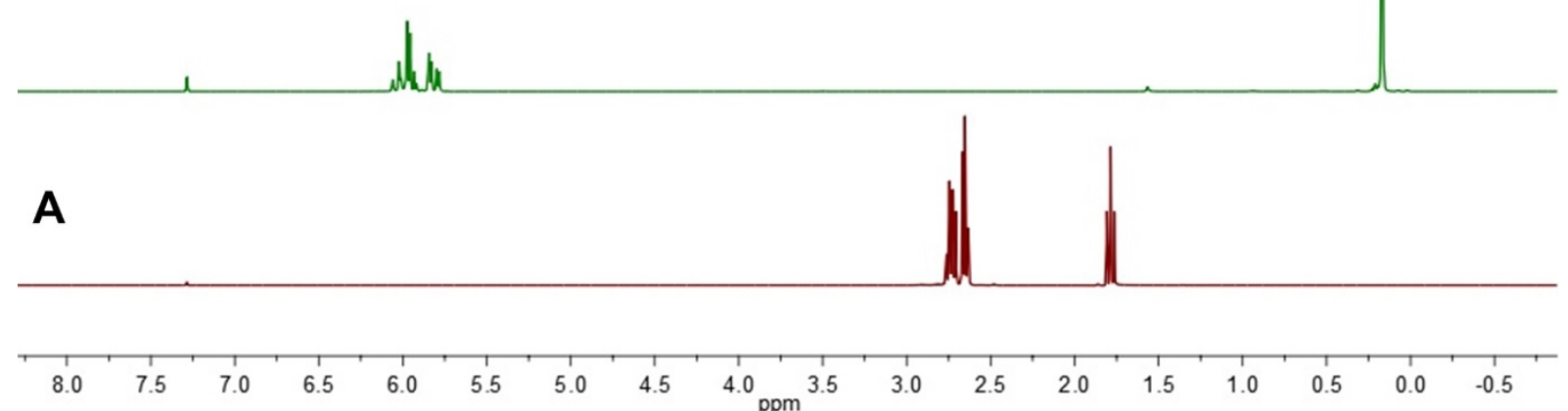

Figure S1. ${ }^{1} \mathrm{H}$ NMR spectra of the 3-mercaptopropionitril (A), of the starting polymer (B), and of $40 \mathrm{wt} \% \mathbf{P 1}$ solution in THF (C). 


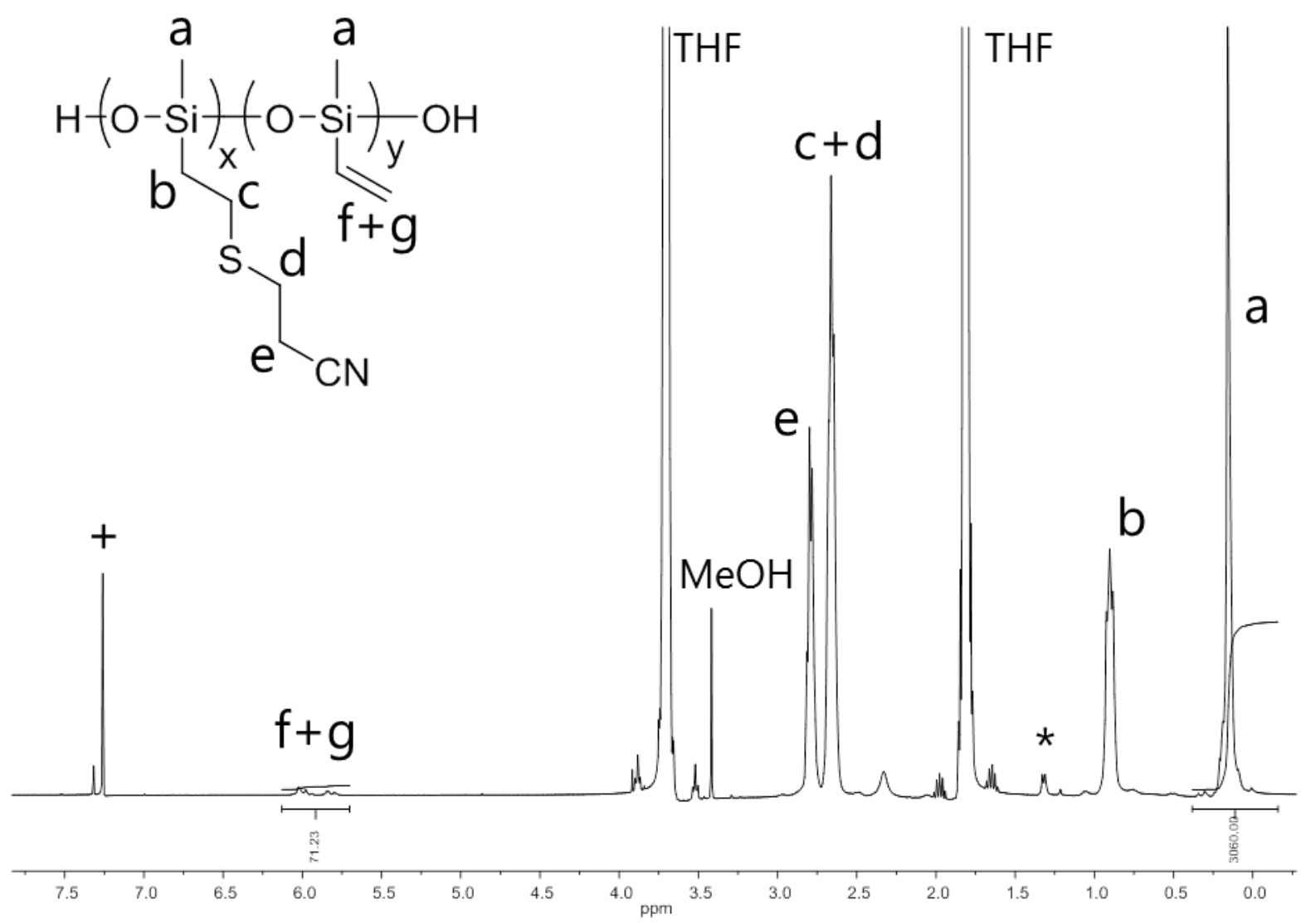

Figure S2. ${ }^{1} \mathrm{H}$ NMR of a $40 \mathrm{wt} \%$ solution of $\mathbf{P 1}$ in THF, with the integrals of protons of vinyl and of methylsilyl groups.

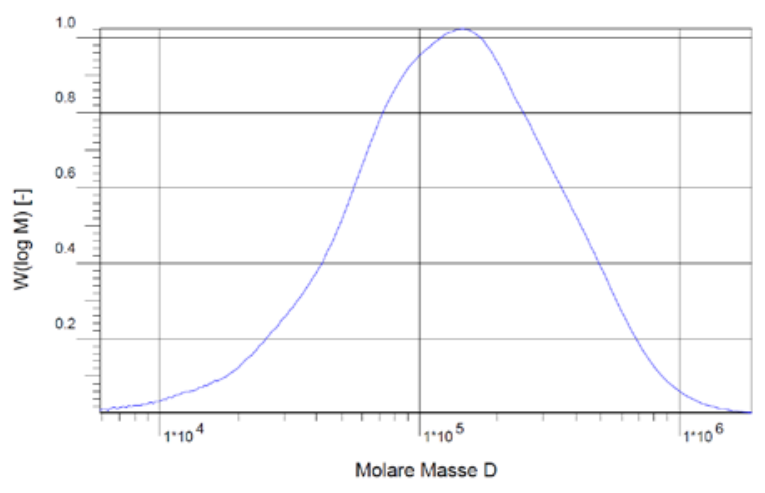

PSS SECcurity RI

$\begin{array}{lll}\overline{\mathrm{Mn}}: & 8.4855 \mathrm{e} 4 & \mathrm{~g} / \mathrm{mol} \\ \overline{\mathrm{Mw}}: & 1.9244 \mathrm{e} 5 & \mathrm{~g} / \mathrm{mol} \\ \overline{\mathrm{Mz}}: & 3.6551 \mathrm{e} 5 & \mathrm{~g} / \mathrm{mol} \\ \overline{\mathrm{Mv}}: & 0.000000 & \mathrm{~g} / \mathrm{mol} \\ \overline{\mathrm{D}}: & 2.2679 \mathrm{e} 0 & \end{array}$

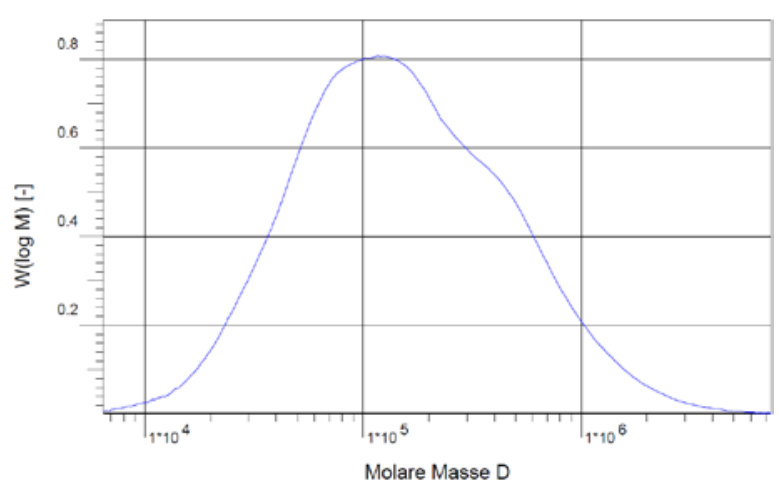

PSS SECcurity RI

$\begin{array}{lll}\overline{\mathrm{Mn}}: & 8.7351 \mathrm{e} 4 & \mathrm{~g} / \mathrm{mol} \\ \overline{\mathrm{Mw}}: & 2.8573 \mathrm{e} 5 & \mathrm{~g} / \mathrm{mol} \\ \overline{\mathrm{Mz}}: & 9.3368 \mathrm{e} 5 & \mathrm{~g} / \mathrm{mol} \\ \overline{\mathrm{Mv}}: & 0.000000 & \mathrm{~g} / \mathrm{mol} \\ \overline{\mathrm{D}}: & 3.2711 \mathrm{e} 0 & \end{array}$

Figure S3. GPC data of starting polyvinylmethylsiloxane (left) and of P1 (right) 

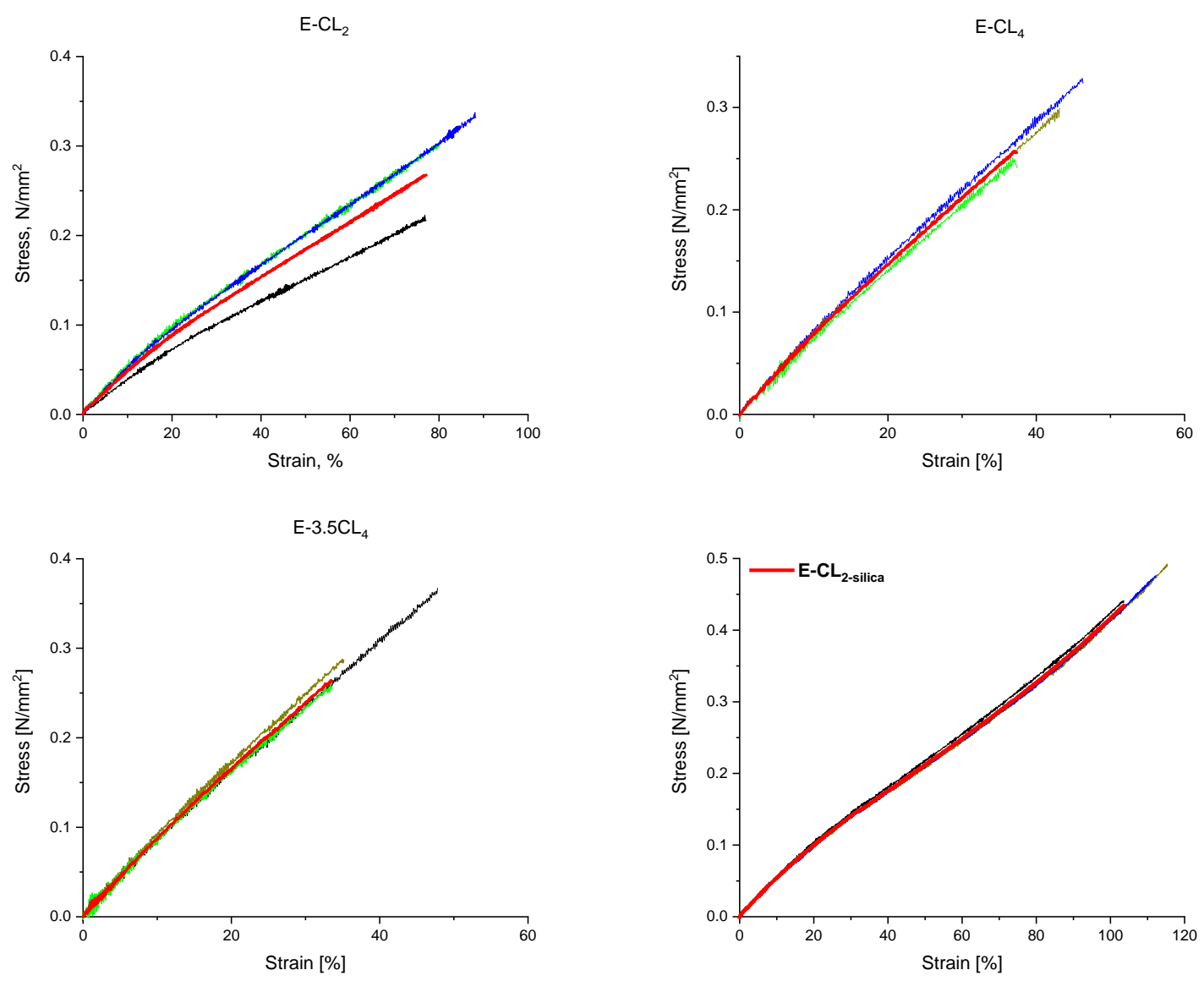

Figure S4. Stress-strain curves E-CL $\mathbf{C L}_{2}, \mathbf{E}-\mathbf{C L}_{4}$, and E-3.5 $\mathbf{C L}_{4}$ as well as of a material E-CL $\mathbf{L}_{2-}$ silica that contains $2.5 \mathrm{wt}$ \% silica. For each material at least three samples were measured. The red curves in the graphs represent the average. On these curves, however the minimum and not the average strain at break is given. 

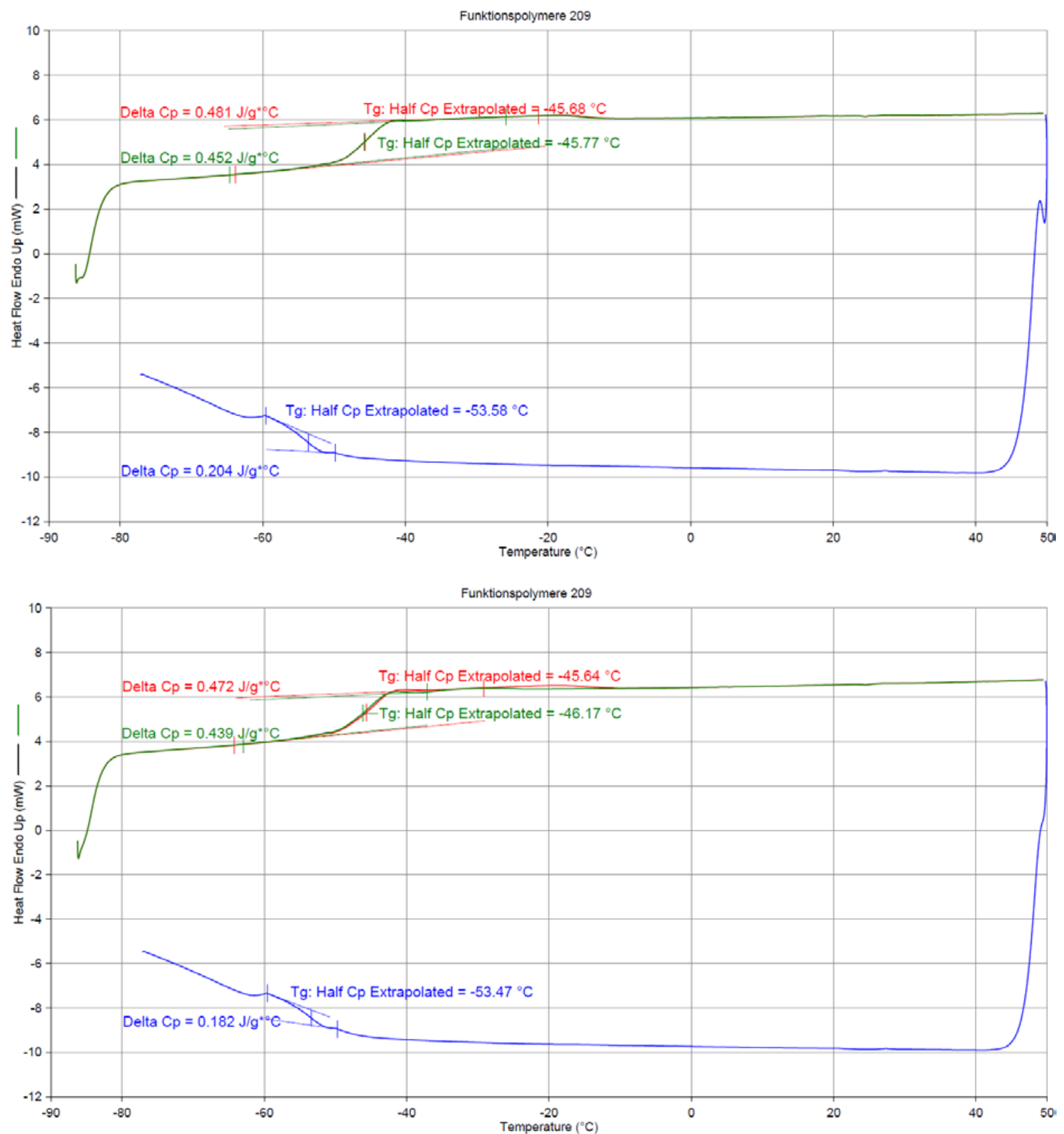

Figure S5. DSC of E-CL 2 (top) and $\mathbf{E}-\mathbf{C L}_{4}$ (bottom). 


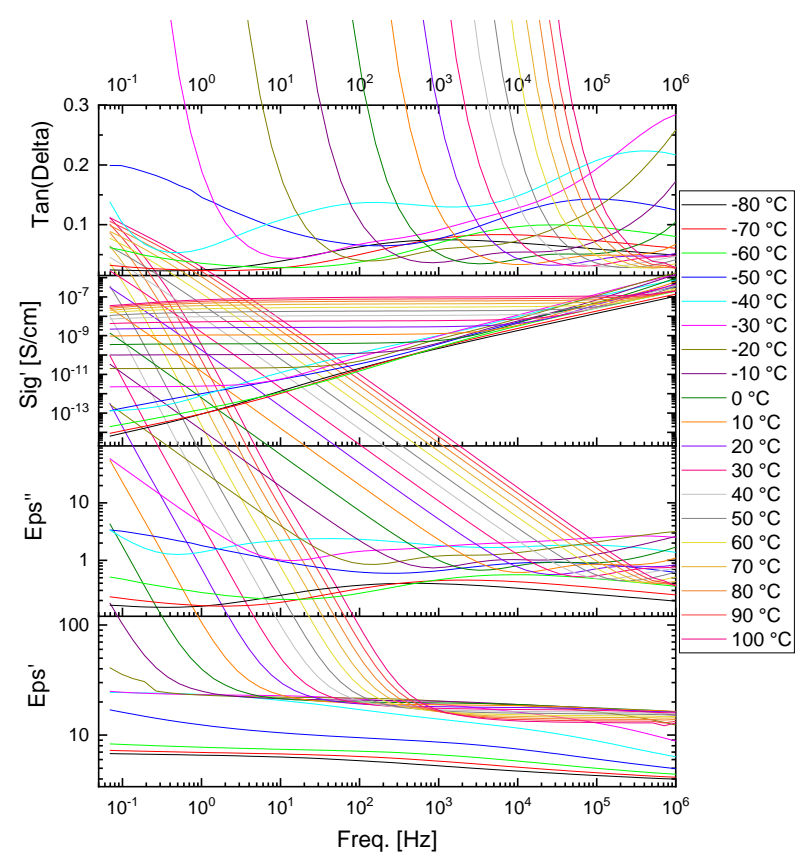

Figure S6. Dielectric permittivity ( $\left.\varepsilon^{\prime}\right)$, dielectric loss ( $\left.\varepsilon^{\prime}\right)$, conductivity $(\sigma)$, and $\tan \delta$ of E$\mathbf{C L}_{2}$ at different temperatures and frequencies. 

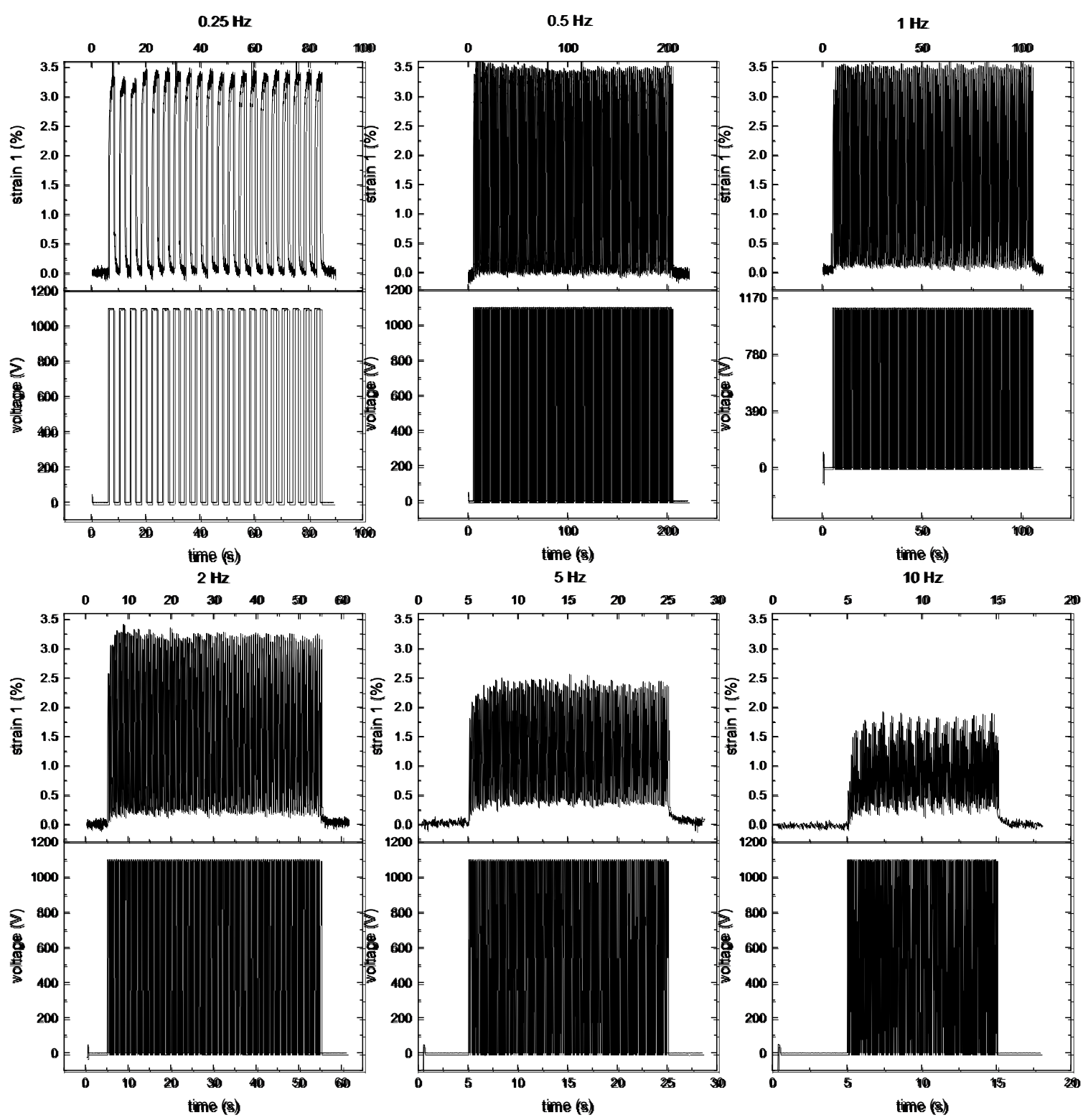

Figure S7. An actuator constructed from a $109 \mu \mathrm{m}$ thick $\mathbf{E}-\mathbf{C L}_{\mathbf{4}}$ film subjected to an electric field of $10 \mathrm{~V} / \mu \mathrm{m}$ and different frequencies of $0.25 \mathrm{~Hz}$ (20 cycles), $0.5 \mathrm{~Hz}$ (100 cycles), $1 \mathrm{~Hz}$ (100 cycles), 2Hz (100 cycles), $5 \mathrm{~Hz}$ (100 cycles), and $10 \mathrm{~Hz}$ (100 cycles), respectively, showed a very stable actuation. 

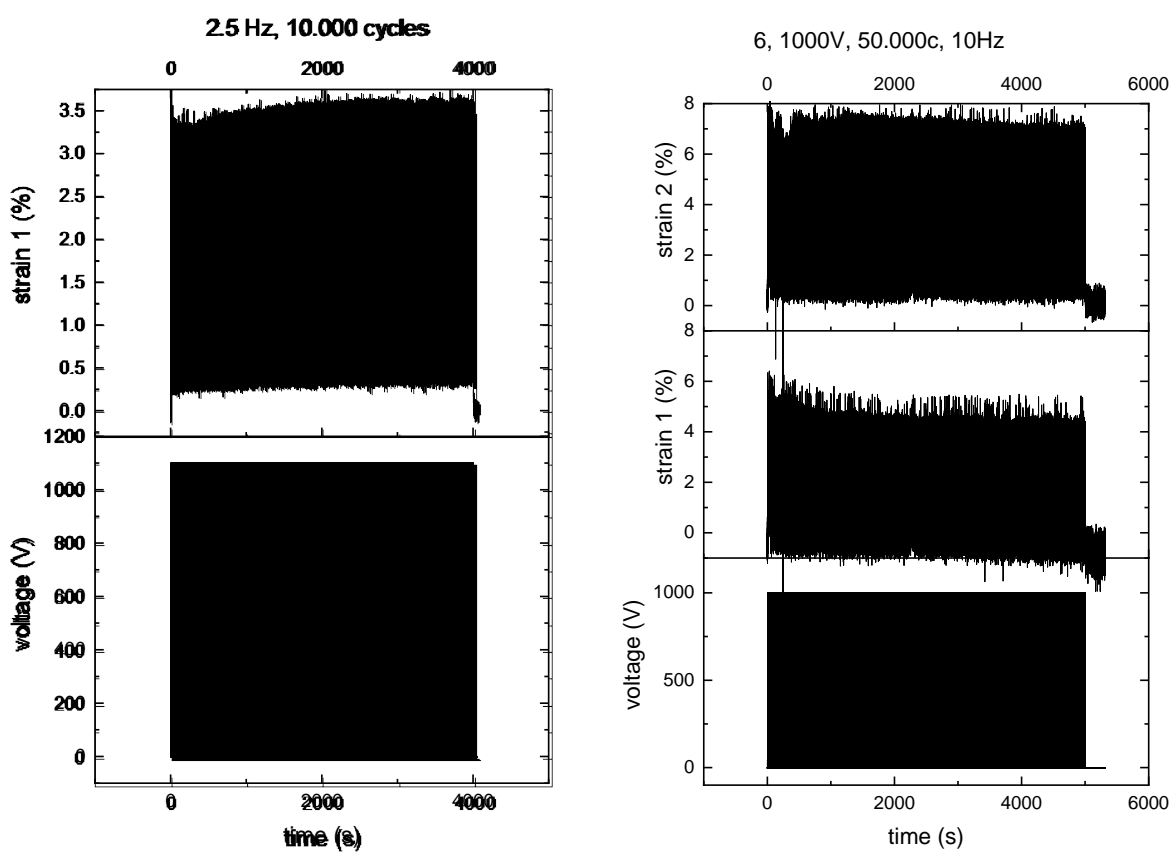

Figure S8. Long term measurements of over 10000 cycles at $2.5 \mathrm{~Hz}$ for $\mathbf{E}-\mathbf{C L}_{\mathbf{4}}(109 \mu \mathrm{m})$ and 50000 cycles at $10 \mathrm{~Hz}$ for $\mathbf{E}-\mathbf{3 . 5 \mathbf { C L } _ { 4 }}(40 \mu \mathrm{m})$ clearly support that the prepared materials are rather robust.

a
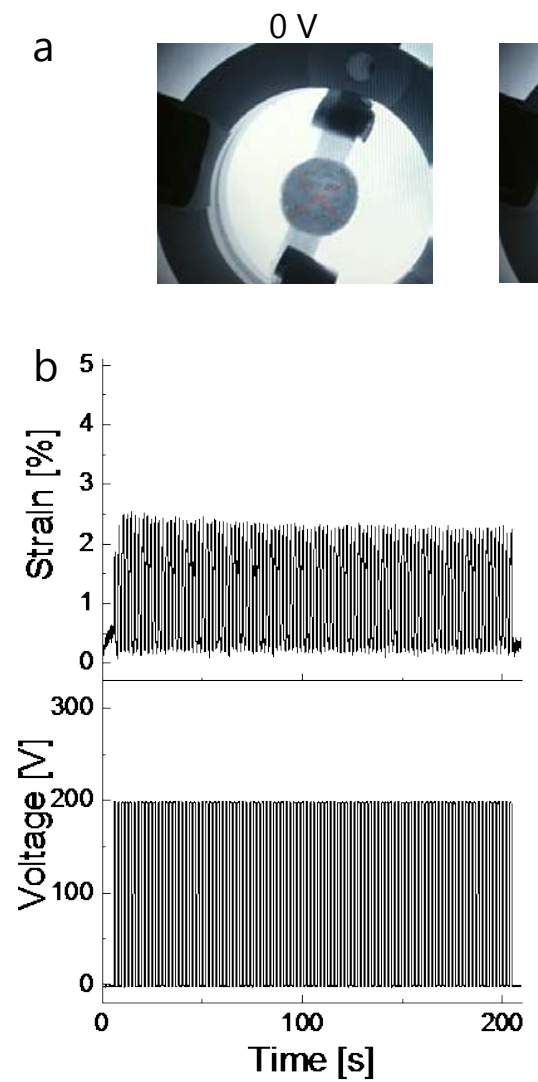

$200 \mathrm{~V}$
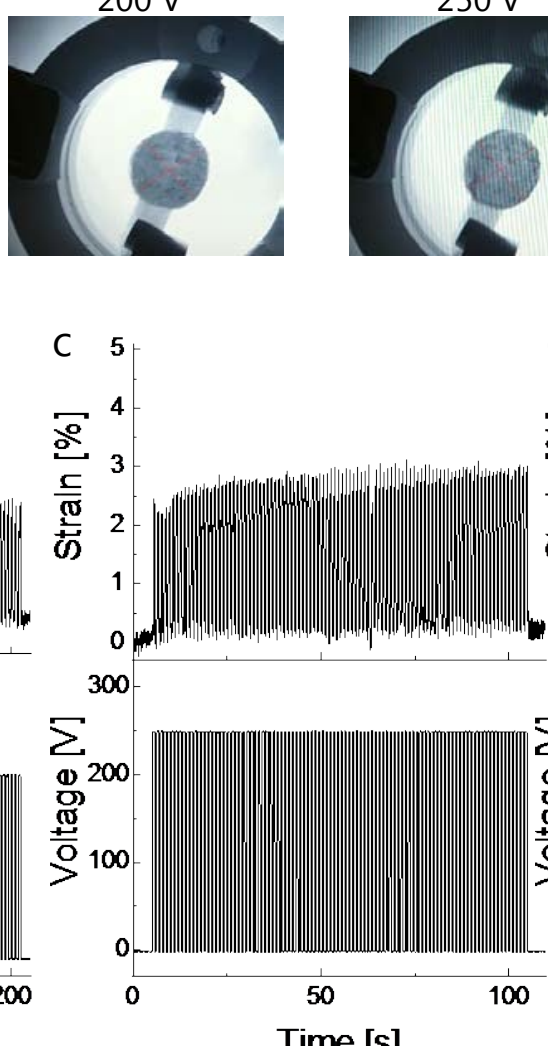

Figure S9. A device constructed from $\mathbf{E}-\mathbf{C L}_{2}$ that gave slightly less actuation.
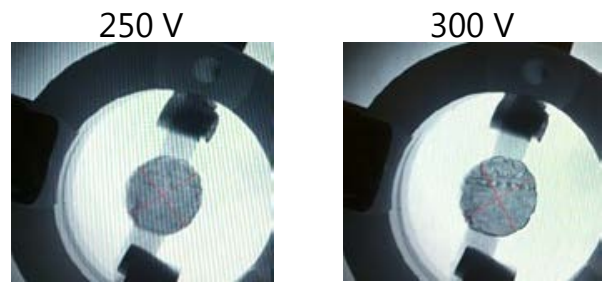

d 5
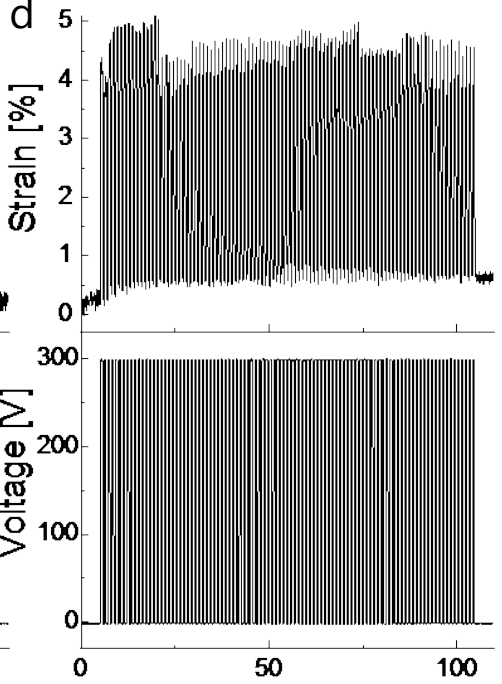

Time [s] 


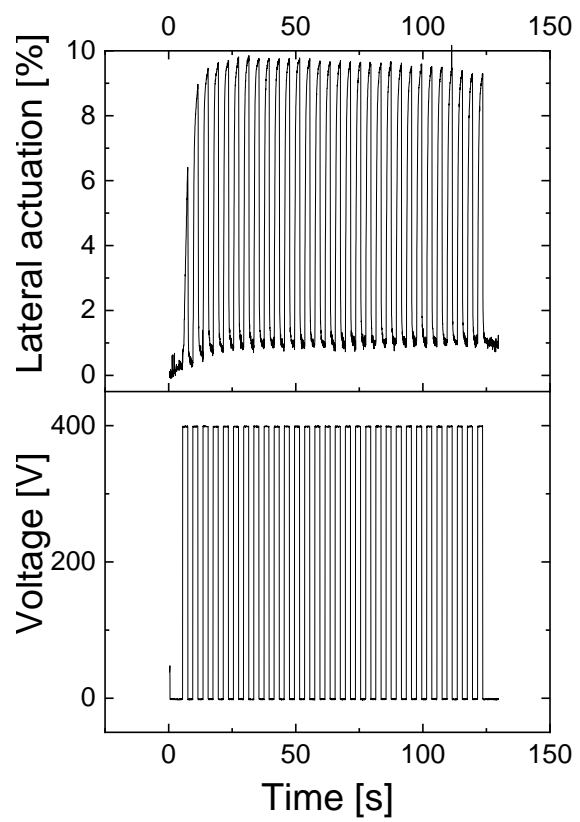

Figure S10. An actuator constructed from E-CL $2(42 \mu \mathrm{m})$ actuated at $400 \mathrm{~V}$ for 30 cycles.

Video S1. 50000 cyclic actuations at $1500 \mathrm{~V}$ constructed from E-3.5CL 4 (36 $\mu \mathrm{m})$.

Video S2. A $23 \mu \mathrm{m}$ thin actuator operated at $150 \mathrm{~V}$.

Video S3. Large out of plane deformation for a $30 \mu \mathrm{m}$ thin film actuated at increasingly high voltages, up to $3000 \mathrm{~V}$.

Video S4. Large actuation of material E-3.5CL $4(19 \mu \mathrm{m})$ at $2000 \mathrm{~V}$. The leakage current is also shown.

Video S5. An actuator constructed from E-CL2 $(23 \mu \mathrm{m})$ actuated at low voltages.

Video S6. Actuation at increasing voltages for E-3.5CL4. $(24 \mu \mathrm{m})$ up to $1000 \mathrm{~V}$.

Video S7. Long term actuation of a device constructed from $\mathbf{E}-\mathbf{C L}_{2}$ at $200 \mathrm{~V}, 300 \mathrm{~V}, 400 \mathrm{~V}$, and $700 \mathrm{~V}$ for the 100 cycles at $1 \mathrm{~Hz}$. 